\title{
A Review on Internet of Things Based Humidifier for Mushroom Cultivation
}

\author{
Dr. Sayyed Naimuddin ${ }^{1}$, Hussain Kasim Ali Ujjainwala², Shreya Khobragade², Shahana Kausar², Krunal Sakhare², \\ Afreen Parveen Sheikh Ejaz ${ }^{2}$ \\ ${ }^{1}$ Professor, Department of EE, Anjuman College of Engineering, Nagpur, Maharashtra, India \\ ${ }^{2}$ Research Scholar, B.E. Fourth Year, Department of EE, Anjuman College of Engineering, Nagpur, Maharashtra, \\ India
}

Article Info

Volume 8, Issue 3

Page Number : 721-725

\section{Publication Issue}

May-June-2021

\section{Article History}

Accepted : 10 June 2021

Published : 17 June 2021

\section{ABSTRACT}

In this study, grey oyster mushroom (Pleurotus pulmonarius) was cultivated in indoor controlled environment to seeking out the possible Risks of contamination and ways of treatment to avoid the contamination. For this, mushroom was cultivated in providing artificial humidifying and Ventilation system to ensure optimum humidity (80-90\%) and fresh air Recirculation in different ways of treatment. The ways of treatment were Included as in position of humidifier, frequency of humidifying, plastic Cork of bags opening part and cleaning of humidifier water container. Maximum percentages of bag contamination (2.5-25.30\%), cap Contamination (5.6-30.75\%), stalk contamination (4.75-23.25\%) and root Contamination (2.6-18.45\%) were found in front to front humidifier Position, long humidifying with long interval frequency, without plastic Cork, without cleaning and bi- monthly cleaning of humidifier water Container treatment but no diseases and pest infection was found. Whereas, Very low percentages of contamination (0.1-0.5\%) were found in Surrounding humidifying position, short humidifying duration with short Interval frequency, with plastic cork and weekly cleaning of humidifier Water container treatment.

Keywords : Internet of Things, Humidifier, Mushroom Cultivation, Pleurotus pulmonarius

\section{INTRODUCTION}

Are commonly known as oyster mushrooms which occupy the second position among most cultivated edible mushrooms worldwide due to their Nutritional and medicinal values [1-3]. Pleurotus spp. Were able to produce a maximum Corresponding author: This is an open access article distributed under the terms of the Creative Commons Attribution License 4.0 Food drying is an industrial process used to reduce water activity in product allowing its conservation, storage stability and transportation. However, the development of new drying techniques or the evalution of new dried products requires a very careful approach. all process involved even in simpler dryers are highly non-linear and its scale-up is

Copyright: @ the author(s), publisher and licensee Technoscience Academy. This is an open-access article distributed under the terms of the Creative Commons Attribution Non-Commercial License, which permits unrestricted non-commercial use, distribution, and reproduction in any medium, provided the original work is properly cited 
generally very difficult, requiring experimentation in laboratory and pilot scales coupled with the experience of the researcher. Hence, a research approach involves basic models that are validated using experimental outcomes. Most of the models require an understanding of the typical product behavior during drying, and most of this information can be drawn from the so-called drying curves that presents the mass decrement versus at time at a stable conditions. Every food has a representative drying curve related to drying air velocity, temperature and pressure that reflects how removal of water is affected during the process using the slope of these curves, is possible to obtain the drying rate curve, which is in turn very important to make assumptions for the construction of mechanics of dried material foods in particular presents, rate-controlling factors in this period are complex, depending upon diffusion through the food, and upon the changing energy binding pattern of the water molecules. There is little theoretical information available for drying of foods in this particular region and experimental drying curves are the only adequate approach. The drying curves are based on the mass reduction with time when the product is dehydrated in a laboratory dryer most of the experimental devices used are composed by a propeller fan, an electric heater, a scale and a humidifier .The temperature and the moisture content of the drying air is keep stable through heating and supply of fresh air or steam , or using saturated air.one of the most important parameters in drying in humidity, but unlike temperature and velocity of air, it is quite difficult to measure it and control it. In earlier experiments the air used had a low humidity or was taken from the environment. This is very simple way to set up experiments, but it has a poor reproducibility because the humidity depends on ambient conditions. In this instance a stream of gas is divided into two parts, one is saturated with water at a certain temperature and the other is a dry gas; both stream are then mixed producing the desired conditioned air. Its most important drawback is the flow rate measurement and the requires an efficient saturation process along with good temperature control of air coming out the saturator. The experimental apparatus normally consists of drying device in which the product sample is exposed to a controlled air flow (Temperature, humidity and speed) and sample zone are quite small.

\section{DESCRIPTION OF THE AUTOMATIC HUMIDIFICATION SYSTEM}

The automatic humidification system is used to control humidity and temperature of air in an experimental facility. This facility has been developed at the automation and control for agro-industrial process laboratory of the Pontifical Bolivarian University, looking forward to emulate ambient air of different climatic zones and to obtain the drying curves of a wide range of agro-industrial products. Fig (1) illustrates the main elements of the test units where the automatic humidification system was set up. It consists of a ring of convective drying where a dryer or a drying box can be placed to evaluate different products. The unit has been instrumented with several temperature, humidity and velocity sensors for air monitoring and strain gages to measure the weight of the product being dried. The experimental apparatus has to produce an important quantity of conditioned air because its major purpose is to evaluate the performance of prototype dryer's .In this unit temperature and humidity of the air are controlled in real time. From one hand, it features an air conditioning unit that reduces temperature and humidity of ambient air depending on the conditions of the convective stream to be use in a particular experiment. Then, the amount the air required in the dryer is extracted by a blower and passed through the Heating Humidification Unit (H2U), which finally delivers the air to the dryer fig (2) illustrates the main features of the H2U. It has temperature and humidity sensors, a set of high pressure water nozzles and a set of electric heaters. 


\section{Design and Construction of a Movable Evaporative Cooling Frame}

Due to the expected increase in air temperature and air capacity as air moves towards the fans, a second wall of evaporative cooling pads was designed and constructed. The Pads were mounted on a frame having the same dimensions as the first wall of Evaporative cooling pads to maintain the airflow rate through the corrugated cellulose Material. The frame was mounted on wheels to test various positions inside the Greenhouse. The corrugated cellulose pads were $0.1 \mathrm{~m}$ thickness with a surface area of $45 \mathrm{~m} 2$ per square meter of pad. Figure 2 shows the movable frame supporting the Cooling pads.

\section{MATERIALS AND METHODS}
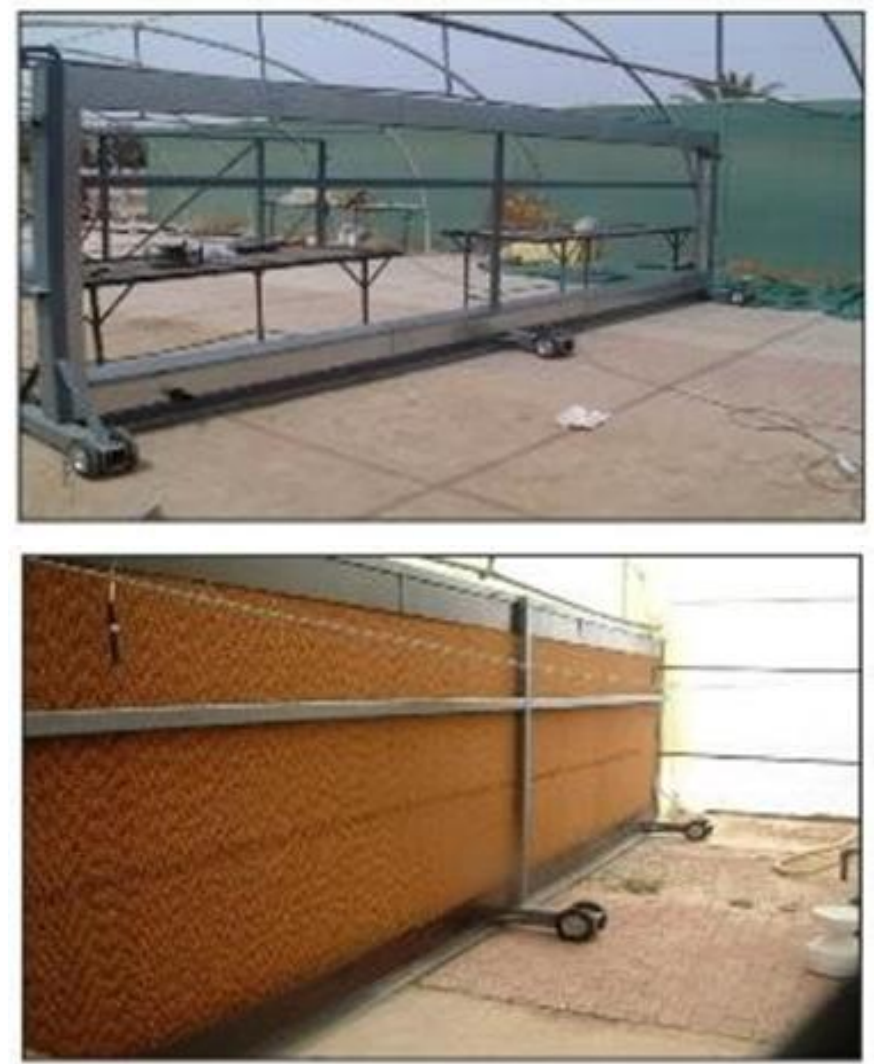

Figure 1. Moving frame mounted on wheels for the second wall of evaporative cooling pads

\subsection{Preparation of mushroom growing bags} Substrate's for preparing mushroom bags were prepared by established mushroom Cultivators. The substrates were formulated by the mixture of saw dust, rice bran and Agricultural lime with the ratio of 100:10:1. The mixtures were packed in autoclavable Polypropylene bags $(6 \times 9$ inch) and sterilized at 20 psi pressure and 1210C temperatures for 6 hours to remove spore of bacteria, fungi and other microorganisms [12]. After Sterilization, it was cooled at room temperature and injected with spawn prepared through Tissue culture technique. Then the opening parts of the bags were closed by plastic cork, Paper and rubber band to protect loss of moisture content from inside the bags and left it vertically for 30-35 days in dark for mycelium colonization. The mycelium colonization was completed when the bags were fully covered by white color mycelium. Then the bags with completed colonization were transferred into a growing room inside a building. Cultivation period was counted from the first day of bags were transferred and arranged in the cultivation room.

\subsection{Design of indoor cultivation room}

The indoor cultivation room was measured at 5.8 $\mathrm{L} \times 4.57 \mathrm{~W} \times 2.74 \mathrm{H} \mathrm{m} 3$ In size. The wall was made by bricks at one side and gypsum board on the rest of the walls. The room was installed with four rows of racks; each rack contained four iron bars distance by $15 \mathrm{~cm}$ from each other and $55 \mathrm{~cm}$ distance between the racks. The room was also installed with roof ventilation system and light in order to facilitate fresh air and maintain proper light intensity respectively. The bags were placed horizontally through the racks by using rope and made it tight by cable tie and hanged vertically. Twelve bags were arranged in one column of rope by 3 bags in together in 4 parts. A total of 100 columns of rope were used to arrange 1200 bags. The columns of rope were arranged at 25 $\mathrm{cm}$ distance from each other in every rack. The distance of the top end bag from the ceiling was 76 $\mathrm{cm}$ and the down end bag from the floor was $30 \mathrm{~cm}$. 


\subsection{Position of humidifier}

After complete colonization the bags were transferred into the growing room and arranged as mentioned above. The humidifiers were placed inside the growing room at two Positions, 'Faced to Faced' and 'Surrounding'. In 'Faced to Faced', the humidifier was Placed between the two columns of bags where the distance from the column to humidifier was $15 \mathrm{~cm}$ in both side and the opening parts (mouth to come out fruit body) of the bags Were faced to the humidifier. In the 'Surrounding', the humidifier was placed also between The two columns of bags but the distance between the opening part of the bags (front view) And humidifier were $25-30 \mathrm{~cm}$, between side view to humidifier were $20-25 \mathrm{~cm}$ and back View to humidifier 10-15 cm (Fig. 1a). In both positions, the humidity was maintained at $80-90 \%$ using the humidifiers. The data was collected on the basis of percentages of bags, Stalk, cap and root contamination.

\subsection{Humidifying frequency}

Two ways of humidifying frequency was conducted; a long humidifying with long interval (LHLI) and short humidifying with short interval (SHSI). In LHLI, two units of humidifier were placed at 3.5-4 $\mathrm{m}$ distance from each other and it was applied 30 minutes with 45 Minutes interval from two positions to maintain $80-90 \%$ indoor humidity. Whereas in SHSI, four units of humidifiers were placed at 2-2.5 m distance from each other's and it was applied 15 minutes with 15 minutes interval from four positions to maintain 80 90\% Indoor humidity. The humidifiers in both treatments were configured as followed by timer: Interval Mushroom was cultivated in this both humidifying system with continuous ventilation. The Data was collected on the basis of percentages of bags, stalk, and cap and root contamination.

\subsection{Plastic cork of bags opening part}

In this method the bags were cultivated with and without the plastic cork that was used in the opening part during substrate packing. After arranging the completed colonization bags In the growing room, 50\% plastic cork were removed and another $50 \%$ were not removed (Fig. 2b). Thus all the bags were cultivated in same environment by providing artificial humidifying and ventilation to maintain $80-90 \%$ humidity and proper air circulation. The data was collected on the basis of percentages of bags, stalk, and cap. Different ways of management for indoor mushroom cultivation.

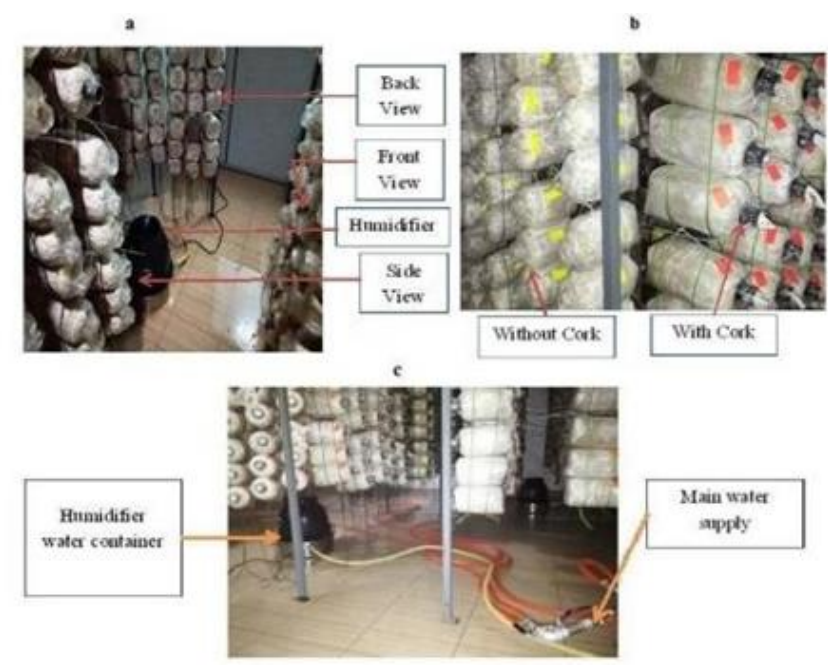

\section{CONCLUSION}

This study found that humidifying application could be imposed contamination for certain Percentages of bags and fruit bodies. Therefore, the management of humidifying conditions as suggested in this study may reduce the risks of disease from water-caused Contamination.

\section{REFERENCES}

[1]. M.A. Khan, M. Tania, S.M.R. Amin, N. Alam, M.N. Uddin, Bangladesh J. Mushroom,2, 17 (2008).

[2]. S.A. Ahmed, J.A. Kadam, V.P. Mane, S.S. Patil, M.M.V. Baig, Nat. Sci., 7, 44 ( 2009).

[3]. U. Lindequist, T.H J. Niedermeyer, W.D. Julich, Evidence-Based Complement. Altern. Med., 2, 285 (2005).

[4]. E.S. Dias, Ciencia e Agrotecnologia, 34, 795 (2010). 
[5]. P. Patel, R. Trivedi, Int. J. Sci. Res., 4, 1126 ( 2015).

[6]. N. Klomklung, S.C. Karunarathna, K.D. Hyde,

E. Chukeatirote, Acta Biol. Szegedlensis, 58, 39 (2014).

[7]. W.S. Kong, Oyster mushroom Cultiv. Part II. Oyster mushrooms. Seoul Heineart Inc.,54 (2004).

[8]. S.T. Chang, Mushrooms as Funct. Foods, 1 (2008).

[9]. K.Y. Jang, C.S. Jhune, J.S. Park, S.M. Cho, H.Y. Weon, J.C. Cheong, S.G. Choi, J.M.Sung, Mycobiology, 31, 145 ( 2003).

[10]. J. Yang, J. Zhao, H. Yu, Y. Wang, R. Wang, L. Tang, Computer and Computing Technologies in Agriculture VI, (Springer, China, 2013).

[11]. J. Deacon, Fungal Biology, (John Wiley \& Sons, UK, 2013).

[12]. R.C. Upadhyay, M. Singh, Industrial Applications, (Springer, Germany, 2011).

\section{Cite this article as :}

Dr. Sayyed Naimuddin, Hussain Kasim Ali Ujjainwala, Shreya Khobragade, Shahana Kausar, Krunal Sakhare, Afreen Parveen Sheikh Ejaz, "A Review on Internet of Things Based Humidifier for Mushroom Cultivation", International Journal of Scientific Research in Science and Technology (IJSRST), Online ISSN : 2395-602X, Print ISSN : 2395-6011, Volume 8 Issue 3, pp. 721-725, May-June 2021. Available at doi : https://doi.org/10.32628/IJSRST2183156

Journal URL : https://ijsrst.com/IJSRST2183156 